\title{
Design by Shape Grammar Precedents as an Experiential Learning Module of Residential Architecture of Amman City
}

\author{
Wael W. Al-Azhari, PhD \\ Department of Architecture Engineering, School of Engineering, The University of Jordan, Amman 11942 Jordan. \\ ORCID: 0000-0001-8158-557
}

\begin{abstract}
Shape grammars are systems of transformational rules that describe the design of a shape. The shape grammar method of precedents description and their interpretation through hybrid grammar that is proposed in this study is conceived to bring logical characteristics to architectural design practice and education.

The study explores applying the shape grammar method to generate precedents description in new design creations. Such a description ensures a logical encoding of residential designs and can be used as a formal method for evolution of hybrid grammars. Al-Lwibda District, in Amman city, with its strong architectural language is chosen as a case study in this research as a teaching module. The aim of the study is to develop various new building prototypes that posses' characteristics of regional architecture transformed into contemporary context.

The study presents applications of hybrid; analysis-original, grammars in the development of residential building types of Al-Lwibda District. It aims to generate new contemporary designs derived from the grammar of Al-Lwibda residential architecture that are coherent with existing context. In addition, new and ongoing issues concerning shape grammars are discussed in order to indicate further directions of their usage in teaching architecture design.
\end{abstract}

Keywords: Shape Grammar, Architectural Design, Architectural Learning, Residential Plan Layouts, Shape Grammar Interpreter.

\section{INTRODUCTION}

\subsection{Aim and Methodology}

The purpose of this study is to show the formal and syntactic information within the plan layouts of Al-Lwibda District residential houses. The plan layouts are the most important characteristic features of these Houses. These characteristics can be defined as design language and shown through an interactive and visual expert system. In this study, shape grammar was chosen as a method, which can be used in analyzing design languages and producing new designs.

The research seeks to understand why the residents of today's buildings are not mostly satisfied with their living spaces and have lost their natural and emotional responses to their place of residence, in regard to our history and culture. The goal of this thesis is to propose a new model for a contemporary house based on the teachings of the Al-Lwibda residential houses. AlLwibda architecture sought to create a vital space, although it faced new issues which raised a kind of tendency towards foreign monuments, it did not deny traditions. Therefore, this study attempts to recognize the relationship between spaces is some houses in Al-Lwibda district in Amman city and propose a pattern for these houses using the shape grammar based on the semantic application of language of shapes and the formability rules. Understanding the past patterns of housing can be a pivotal step towards a better future. This is important in terms of both theoretical and practical aspects. From the theoretical point of view, it is possible to read and analyze the shape grammar theory in these residential houses, which can be pursued elsewhere in Jordan; the practical aspect is associated with design programs and activities in teaching architecture design.

In the early 1990s, shape grammar was used to teach architectural composition to students at Harvard University, MIT, UCLA and the University of Lille. With the use of shape grammar, students were, in fact, able to apply design language in building design (Knight, 1981).

\subsection{Design Languages and Shape Grammars}

People use natural languages to maintain daily relationships. Languages may change or develop but in a long time. Language is an abstract definition to show and explain the reality. On the other hand, artificial languages are special communication tools invented by the people. As an example, music notes are a part of a special language used by musicians. Moreover, Fortran and Pascal are computer based artificial languages (Raphael, 1976).

Language consists of arrangements of the words in its own vocabulary. Likewise, design is an organization of design components. New designs are produced with new arrangements of shapes (Wojtowicz and Fawcett, 1986).

Many literatures emphasize that there is a strong relationship between the structure of language and architectural design. Languages have a grammar that defines the combining rules of words. As mentioned on languages features, a similar approach for combining design shapes is possible (Guzelci, 2014).

In the 1980's the researchers focused on the architectural designs, which are belonging to an era, an architect or a region. Each of these architectural languages that belong to a certain era or an architect has its own compositional principles. These architectural principles are defined with the set of rules and these made up to the grammar of that language (Stiny, 1980).

In architectural design the number of created combinations is numerous. However, it cannot be said all combinations are meaningful. In this point, shape grammar includes the rule set to provide the appropriate relationships between these components.

Shape grammar is a method introduced by Stiny and Gips (1972), enabling the analysis of design languages of 
algorithmic structure and the production of new designs in the same language. A shape grammar exists of rules that can be applied recursively onto a shape which results in new shapes.

Shape Grammar can be defined as a rule set which is deployed to form a design language. As linguistics does not invent a new language, shape grammar does not invent a new architectural language. It consists of generative rules used to produce shapes. Repeated application of shape 1rules to an initial shape lead the generation process of new shapes, Figure 1. A sequence of derivation often generates shapes that are unexpected (Stiny and Gips, 1972).

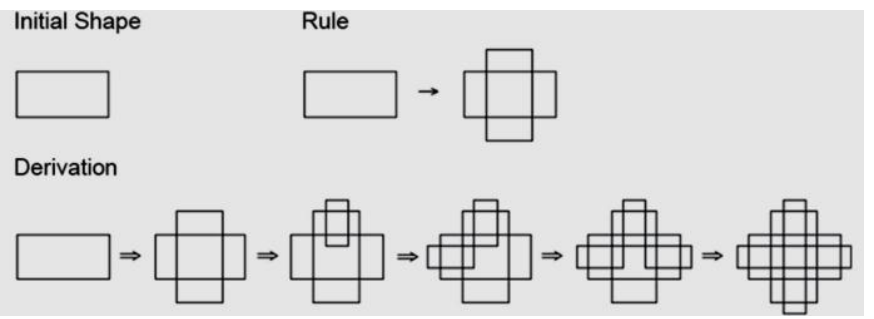

Figure 1. Applying the rule on an initial shape. Source: (Knight and Stiny, 2001).
Fasoulaki (2008) argued that form grammars are specific categories of rule-based professional systems in artificial intelligence that generate geometric shapes. A shape grammar consists of shape rules and a generation engine that selects and processes rules recursively, ranging from an initial shape. Rules are adapted to specify the way of replacement particular shapes and to explain the way of replacement. Boolean operators can be used to apply transformations to a shape. The four possible operators are addition, subtraction, product, and symmetric difference. The operators work mostly in combination with one or more (Euclidean) transformations. Figure 2.

Al-Lwibda residential architecture language is evolved in a long term with additive and repetitive process. The language of this architecture is complex but the whole keep architectural orders and information. This architectural information underlying Al-Lwibda design language can be defined through an algorithm. It is possible to analyze and decompose this architecture language. Decomposition is made by exploring the components and the rules of combining rules for these components. The components and the rules formalize the grammar of the language.

Translation
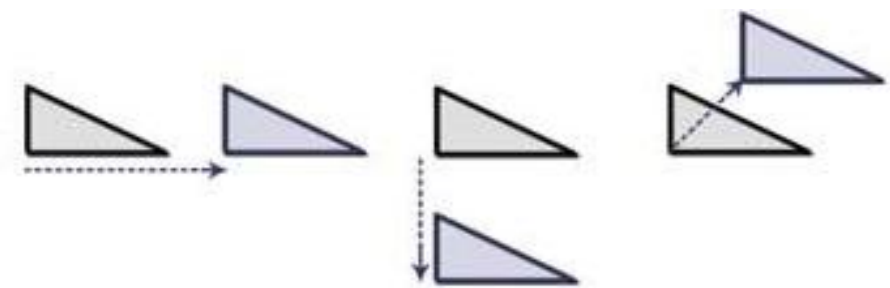

Rotation

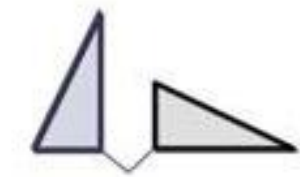

Reflection
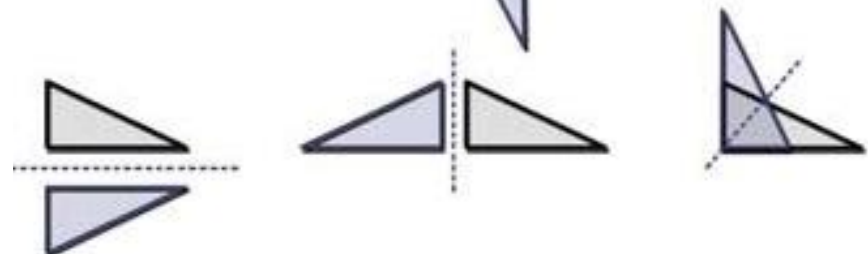

Scale
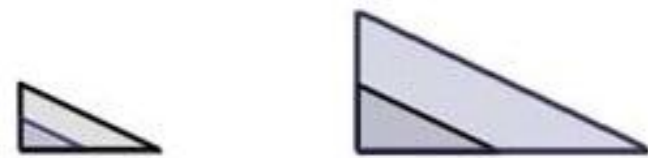

Combination of Transformation
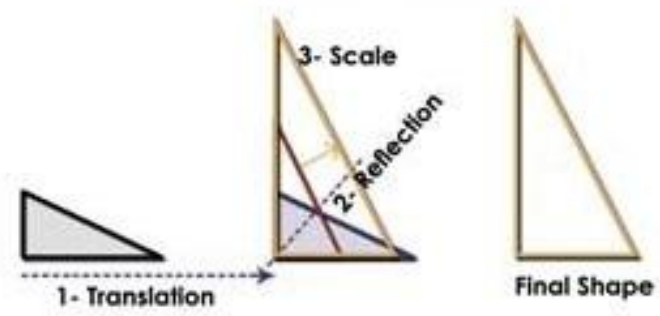

Figure 2. Euclidean Transformations of Shapes. Source: (Knight, 2000). 
International Journal of Engineering Research and Technology. ISSN 0974-3154, Volume 13, Number 10 (2020), pp. $2526-2535$

(C) International Research Publication House. https://dx.doi.org/10.37624/IJERT/13.10.2020.2526-2535

\section{Al-Lwibda Residential Houses in the Context of Shape} Grammars

\subsection{Main Features of Al-Lwibda Residential Houses}

Al-Lwibda is one of the oldest and most revered neighborhoods in Amman city, Figure 3. It is a neighborhood that is both benefiting and suffering from the growth of business, a burgeoning arts and culture scene, and an influx of outsiders (both Jordanians and foreigners), who have descended on the region. Despite the fact that Al-Lwibda is primarily a residential area, it is quickly becoming a destination in Amman city, with shoppers and café-goers crowding the narrow streets (Dilworth, 2017).

The architecture of that era began to show the features of modernity and the Art Deco model, which was mixed with construction techniques. The traditional stone in the Levant, which is still visible today to some buildings and houses in the city center, Jabal Amman and Jabal Al-Lwibda, which dates back to that period.

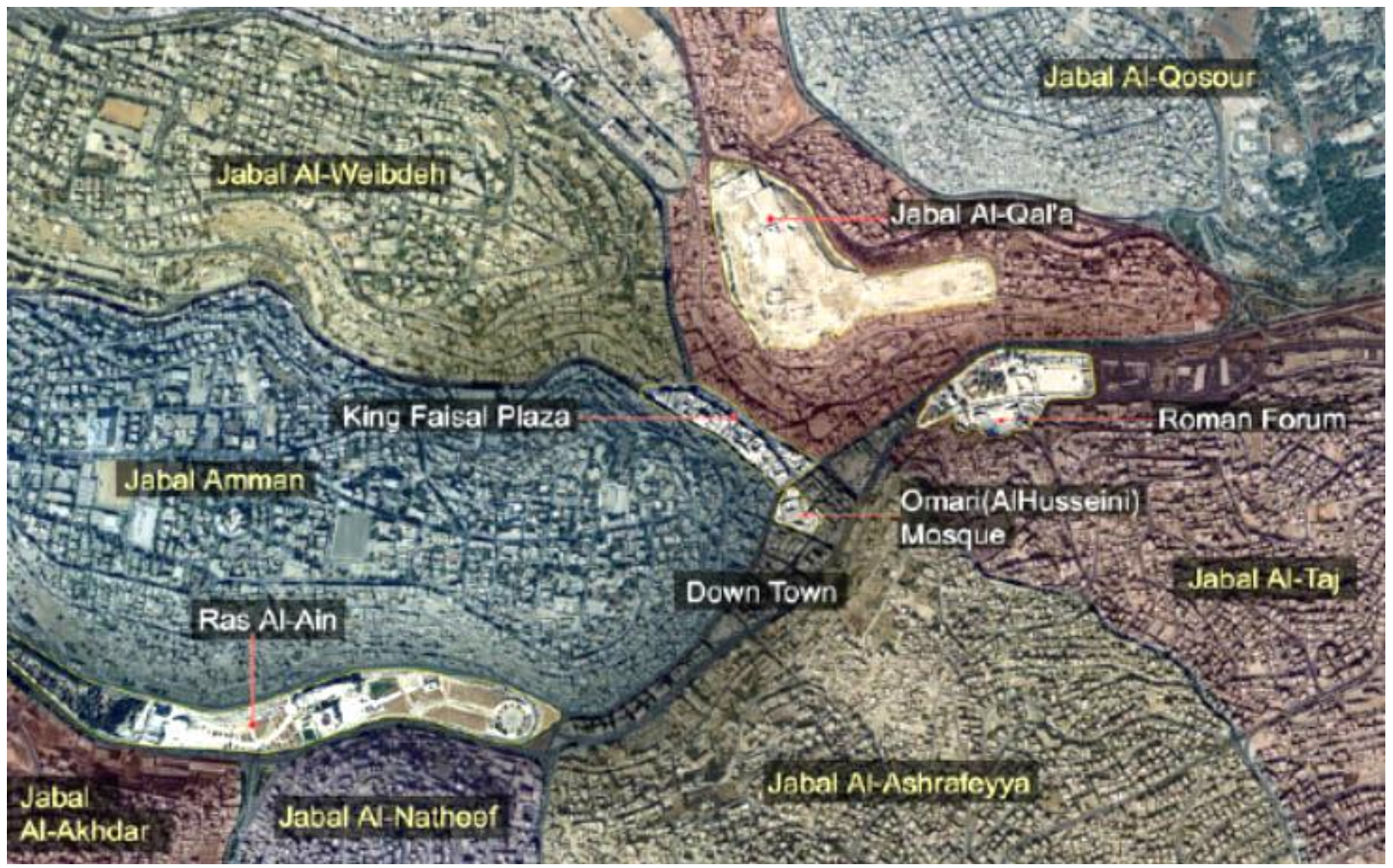

Figure 3. The Location of Al-Lwibda District in Amman City. Source: (Abu Ghoush, 2012).

Various types of Al-Lwibda houses were evolved under different geographic features, climates and traditions. In spite of all this diversity, some features of the these houses are remained unchanged in many regions. As Daher (2014) stated, all Al-Lwibda houses have certain characteristics in common. The plan layouts of the houses are the most important characteristic.

In general, buildings in Amman city are classified into four sections (Daher, 2009):

1. One floor with a central corridor.

2. The housing of the city of Levant, with a commercial activity on ground floor.

3. Local character, with an industrial activity.
4. Modern Amman houses.

5. Open global system.

6. Apartment buildings.

Al-Lwibda residential houses usually have one floor. Over time, houses floor quantity has increased. Even the number floor is increased; the main living floor is generally located at the highest level. The plan layouts of main living are presenting the common language that belongs to these houses. The architectural language of the houses consists of the organization of rooms, halls, Diwan, and the bays, Figure 4. The organization of these plan elements is a main issue. For this reason, certain details of house plans are ignored in the scope of this study. 
International Journal of Engineering Research and Technology. ISSN 0974-3154, Volume 13, Number 10 (2020), pp. 2526-2535

(C) International Research Publication House. https://dx.doi.org/10.37624/IJERT/13.10.2020.2526-2535

\subsection{Elements in Al-Lwibda Residential Houses Plan Layouts}

The elements that composing Al-Lwibda houses plan layouts are examined. These elements are rooms, halls, Diwan, and the bays.

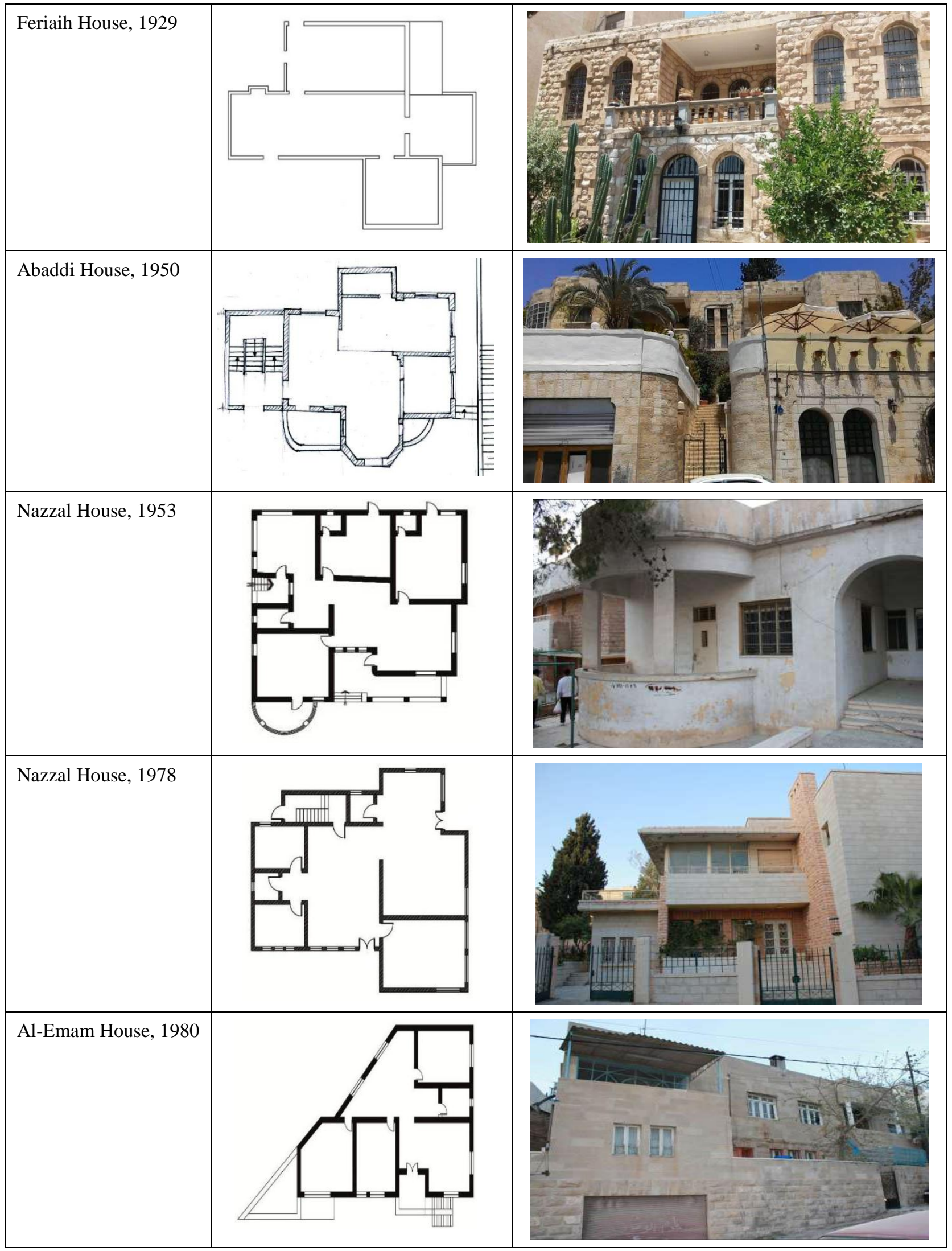

Figure 4. Different types of Al-Lwibda Residential Houses.

Source: (Al Adayleh, 2018 and The University of Jordan Publications, 2010, adapted by the Author). 
The rooms are the most important design elements which affect the shapes and the types of the plans. There are some types of plans which can only be realized with a determined number of rooms, just as there are some other plans in which the number of rooms is necessarily limited. Whether the rooms are aligned in one single direction or more determines the plan type. Some rooms are more valuable than others according to their location in the plan layouts. The bays are added to the rooms and are located on the façade of the rooms, generally to provide more daylight and aeration, or in some cases to improve the shape of the room. They are a common characteristic in all of the plan types.

The hall was an open passage-way connecting the rooms. This type of hall was improved step by step and was finally placed within the house at one side, or between two rows of rooms, or in the middle. In addition to being a circulation area, the hall was also the place where the whole household assembled. The areas free from circulation were used as sitting areas.

The Diwan is a more protected place for sitting and some halls are provided with more than one of them. It is a more protected place for sitting and some halls are provided with more than one of them. The hall is the most influential element in the composition of the plan. The type of the house is determined directly by the shape and location of the hall. According to the location of halls plan layouts are classified as without a hall, with an inner hall, and with a central hall. Graphical representation of hall types can be seen in Figure 5.

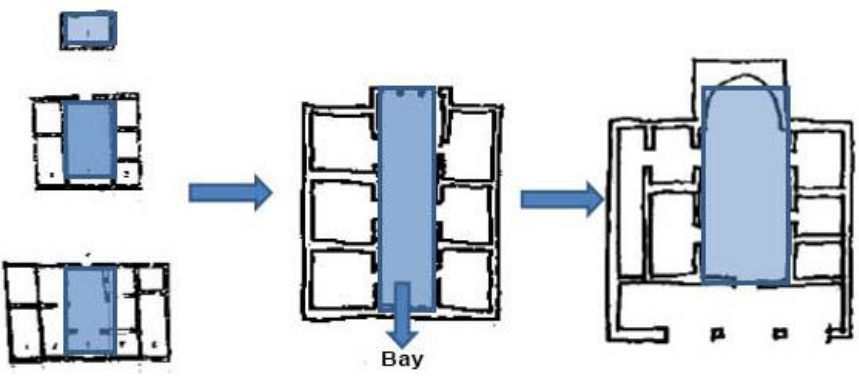

Figure 5. Plan Types and Plan Components of Al-Lwibda Houses.

Source: (The University of Jordan Publications, 2010).

Rooms on a single row can divided with the Diwan. It is an additional hall to get sunlight into the hall and to reach the courtyard from hall.

The bays are generally added to enlarge the interior volume of the house. Another purpose to add bays is to get sunlight and gravitate to view. Bays are generally located on the outer border of rooms but in some plan types, bays are used as an extension of hall.

In the early examples of these houses, the stairs were very steep, in one flight, and they were located on the external side of the hall. Later on, they were placed between the rooms in a row and had two flights. In time, they became wider and were built in three flights.

\subsection{Shape Rules to Generate Al-Lwibda Residential Houses Plan Layouts}

Although this classification includes most of the types of A1Lwibda houses, there are some other house plans that cannot be included in these types. These houses were classified according to their plans, shapes, and compositions and not according to the conditions of land and climate. In some large houses and palaces of differing sizes, more than one type of plans may be combined. These combinations were not new plan types; they were generated by using more than one plan type or repeating a certain plan type twice or more. Large houses and palaces with one, two, three halls were designed by using this method.

\section{Plan Type without a Hall}

This is the most primitive type of Al-Lwibda houses and consists of one or more rooms in a row. There is a circulation area in front of the rooms in the shape of a courtyard. When the rooms are above ground level, this area takes the form of a balcony.

\section{Plan Type with an Inner Hall}

In this type, both sides of the hall are surrounded by rows of rooms. This plan type is developed by adding another row of rooms onto the outer side of the hall. In some plans, the inner hall is extended towards a room which is smaller than the other rooms in the row. In some other plans, the hall is extended by adding another hall or a Diwan. This type may have several sub-types because of these variations. In some cases in this group, the corners of some rooms are also inflected in order to provide entrance, Figure 6.

\section{Plan Type with a Central Hall}

This type represents the third and the last stage in the development of the plan layouts. The hall is located in the middle of the house and is surrounded by rows of rooms on all four sides. It is oval or square in shape and has curved or inflected corners in some cases. Among the rows of rooms are one or two Diwans in the form of recesses, which are always located on the axis of the hall. By changing the numbers of Diwans from two to four, variations and combinations are generated in this plan type, Figure 5.

\begin{tabular}{|c|c|c|c|c|c|c|c|}
\hline & & 1 & 2 & 3 & 4 & 5 & 6 \\
\hline & & 1 Room & 2 Rooms & 3 Rooms & $\begin{array}{l}\text { With a Diwan in } \\
\text { the Middle }\end{array}$ & $\begin{array}{l}\text { With a Diwan in } \\
\text { the Side }\end{array}$ & $\begin{array}{c}\text { With a Central } \\
\text { Hall }\end{array}$ \\
\hline \multirow{3}{*}{ A } & $\begin{array}{c}\text { Plan Type } \\
\text { with an }\end{array}$ & & & & & & \\
\hline & Inner Hall & - & & & & & \\
\hline & & A1 & A2 & A3 & A4 & A5 & A6 \\
\hline
\end{tabular}




\begin{tabular}{|c|c|c|c|c|c|c|}
\hline & 1 & 2 & 3 & 4 & 5 \\
\hline \\
\hline $\begin{array}{c}\text { Plan Type } \\
\text { with a } \\
\text { Central } \\
\text { Hall }\end{array}$
\end{tabular}

Figure 6. Plan Types with an Inner Hall and a Central Hall. Source: (The Author, 2020).

\section{A PARAMETRIC SHAPE GRAMMAR}

\subsection{A Computer-Aided Design System}

In this section, a parametric shape grammar developed to generate the plans of Al-Lwibda houses. Parametric shape grammars are variations of shape grammars in which shape rules are defined in terms of shape rule schemata. A shape rule schema $(\alpha \rightarrow \beta)$ consists of the parameterized shapes $\alpha$ and $\beta$ (Stiny, 1980). In design, the term schema is often used to represent the properties of a formal structure. In the parametric shape grammar, a shape rule schema is applied by the replacement of the shape on the left-hand side $(\alpha)$ with the shape on the right-hand side ( $\beta$ ). As Mitchell, et.al. (1991) stated the shapes that appear in rules may be actual construction elements and spaces, or they may be abstract shapes and volumes that serve as construction lines, grids, axes, placeholders for later substitution of something else, and other devices that guide the development of a design.

In a syntactic or a compositional context, a design can be defined as a complex of shapes and the relationships between these shapes. A shape grammar (SG) contains a vocabulary (V), a set of spatial relations defined by shape rules (R), and an initial shape (I) made up of the shapes in the vocabulary. By applying the shape rules recursively to the initial shape, a formal composition of design can be generated (Stiny and Gips, 1972).

Shape grammars are formed using various language-theoretic operations, such as shape operations, set operations, and substitution (Stiny, 1980). While in shape grammars, shapes made up of lines and points constitute the vocabulary elements, in set grammars, which are conceptually simpler forms of shape grammars, discrete elements constitute the vocabulary. As Coyne (1988), stated that a set grammars have certain implementational advantages compared with shape grammars. Set grammars are more amenable to representation within a computer-aided design system, and they also seem to conform better to the designer's world.

\subsection{Shape Grammar Interpreter}

Shape Grammar Interpreter are expert system that allows users to develop or generate designs. A Shape Grammar interpreter is a computer based system that can make operations. With using these systems development of these design alternatives can easily created in an interactive way (Trescak, Esteva, and Rodriguez, 2012), Figure 7.

Early shape grammar expert systems were implemented and developed by Krishnamurti and Giraud, 1986). Their approach is defending the need of algorithms for performing the shape rules. First visual shape grammar interpreter was done by Tapia (1999), who developed a 2D shape grammar interpreter that is able to work on an entire shape with Euclidian transformations. Such interactive systems enable user participation in design process.

Processing is a very flexible interface to create $2 \mathrm{D}$ geometric compositions. First, design components are defined on a $2 \mathrm{D}$ analytic plane by using coordinates. Shapes, sizes and the label are also specified. The combination rules of components and restrictions are also defined. Processing interface is used to interpret all information about components.

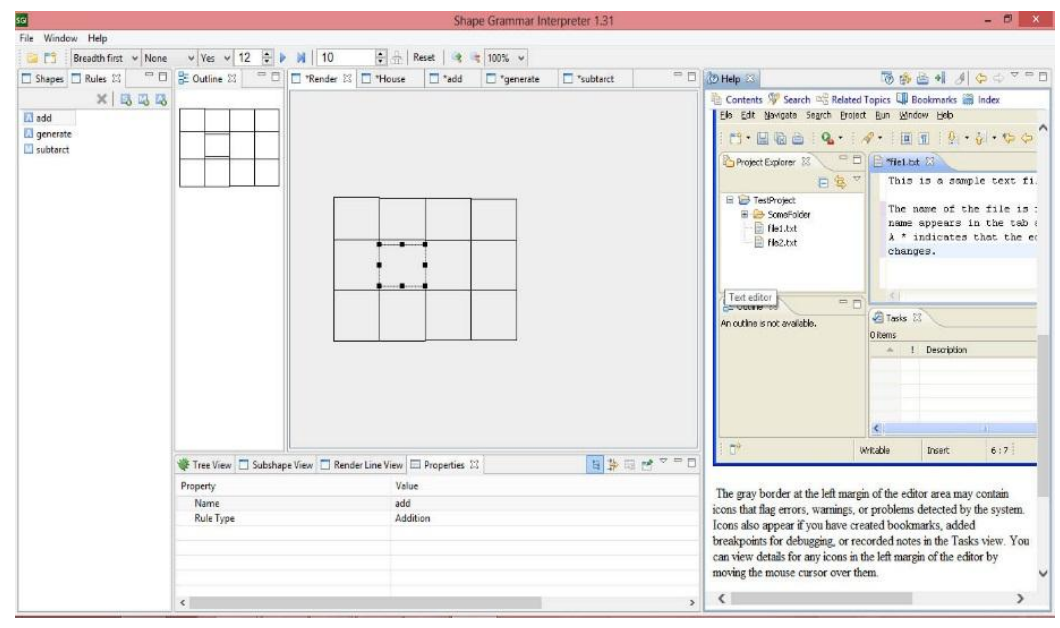

Figure 7. Shape Grammar Interpreter Interface, v. 1.31.

Source: (https://sourceforge.net/projects/sginterpreter/, June 2020, adapted by the Author). 
Generation process of plan layouts is specified with a verbal algorithm and flowchart. Instructions about generation process are displayed to help the user while the code is running. Interface has coding screen, display screen and an interactive screen. Users have the chance to lead the process by the help of keyboard on interactive screen. Keyboard places the components into plan layouts due to the rules and restrictions (Guzelci, 2014).

\subsection{Algorithm Schema of the Compositions}

After understanding the processing operation, it is essential to give the working process of algorithm schema. Algorithm schema is leading the user to define the size of layout in coding screen. After defining the size of layout the code is run. First, user is expected to create hall, which is the main element of AlLwibda houses plan layouts. In the next step, the rooms are located around the hall. The number of the rooms can be 2, 4, or 6 based on grammars. Operation of adding rooms is reversible. It means layout with a 4 rooms can transformed into type with 2 rooms by deleting 2 rooms. Another plan element Diwan can be added to plan layouts. The Diwan can only added to plan layouts with 4 or 6 rooms (Guzelci, 2014).

Before lasting the generation process, user can create bays. The bays are added randomly to plan layout on every pushing to the button. After completing the code, the expert system based on an algorithm is run and new steps and new components are added based on grammar rules, Figure 8 .

\subsection{Rules on Creation Design Process}

The system is running on an order, which is defined on algorithm scheme. The generation process is explained step by step below. The layout is the area where the design alternatives created on. Before running the processing code the size of the layout has to be defined by the user in coding interface. Processing interface draw the layout once as a background.

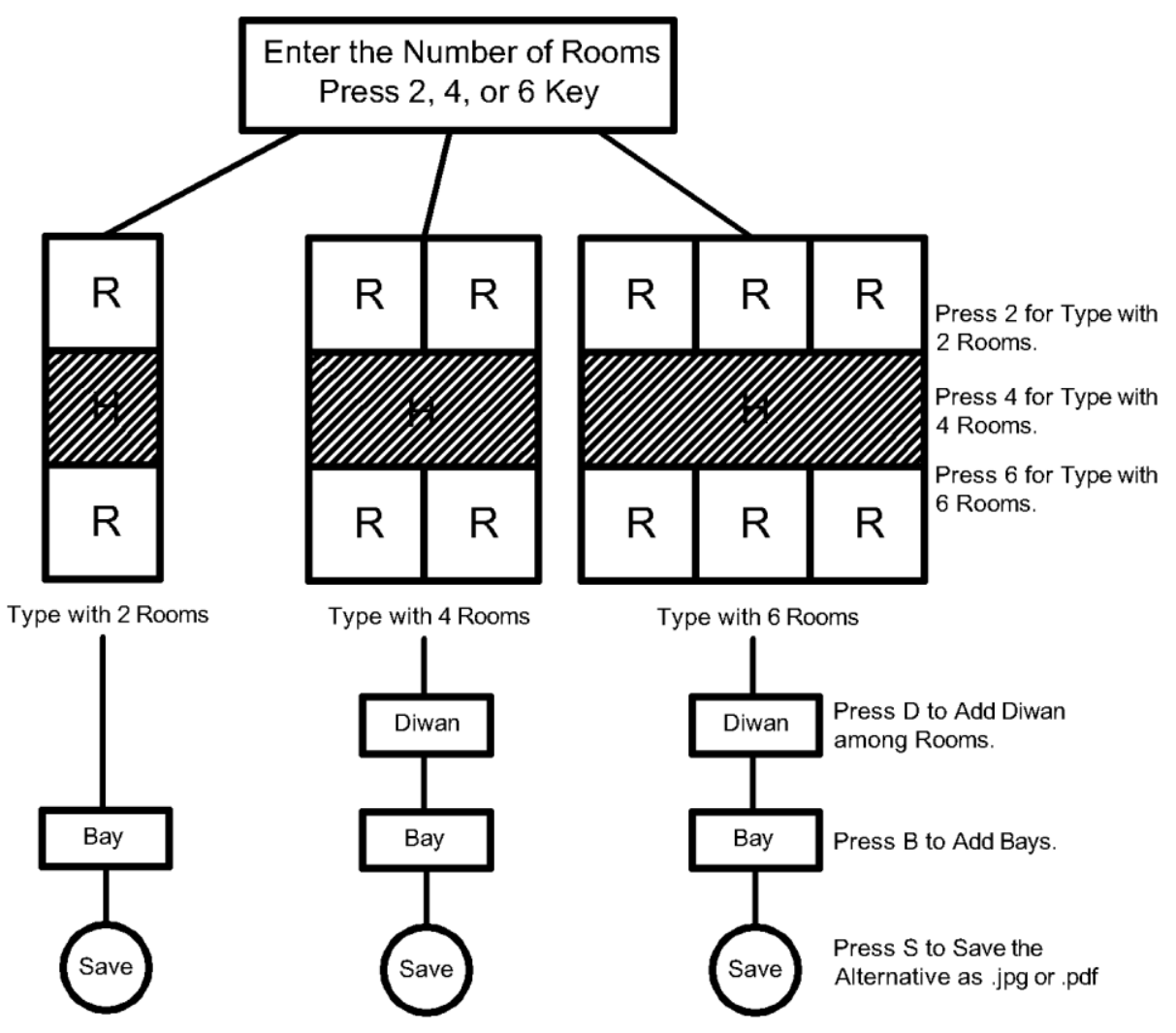

Figure 8. Algorithm Representation of Design Components. Source: (The Author, 2020).

Changing the size of layout is not possible during the code is running. The user enters the width and length as parameters. Every created plan layout based on a grammar has to include a hall. The system is able to produce only plan layouts with an inner hall. After running the code, the system automatically draws the background to place the plan components. Afterwards, system communicates with user from the instruction display screen (Guzelci, 2014).
Placing hall is the first step to generate a plan layout. "Push the letter $\mathrm{H}$ from keyboard to place the hall". By pushing to " $\mathrm{H}$ " button from keyboard, system places a hall at the middle of the layout. The houses with inner hall may have 2, 4, or 6 rooms. The software consults the user to choose one of these alternatives. User press the button " 2 " from keyboard to create 2 rooms, press " 4 " to create 4 rooms or press " 6 " to create 6 rooms. The rooms are located on the both side of the hall on 
y-axes. Having 4 or 6 rooms create 2 rows this also enlarges the hall, which is a passage between rooms.

Houses with 4 or 6 rooms may have 1 or 2 Diwans. Users press "D" button to place a Diwan between rows of rooms. With this operation, plan layouts with 3 and 5 rooms are created. Bays can be located on outer edges, which is not neighbor with the hall. To locate bays user press button " $\mathrm{B}$ " for types with 2,4 , or 6 rooms. This operations start to create random bays on the edges which is not neighbor with halls.

Using the shape grammar, various types of patterns can be created in the form of sub-shapes and enhance the richness of spatial configuration. A sample of design process can be extracted from the decision tree, Figure 9.

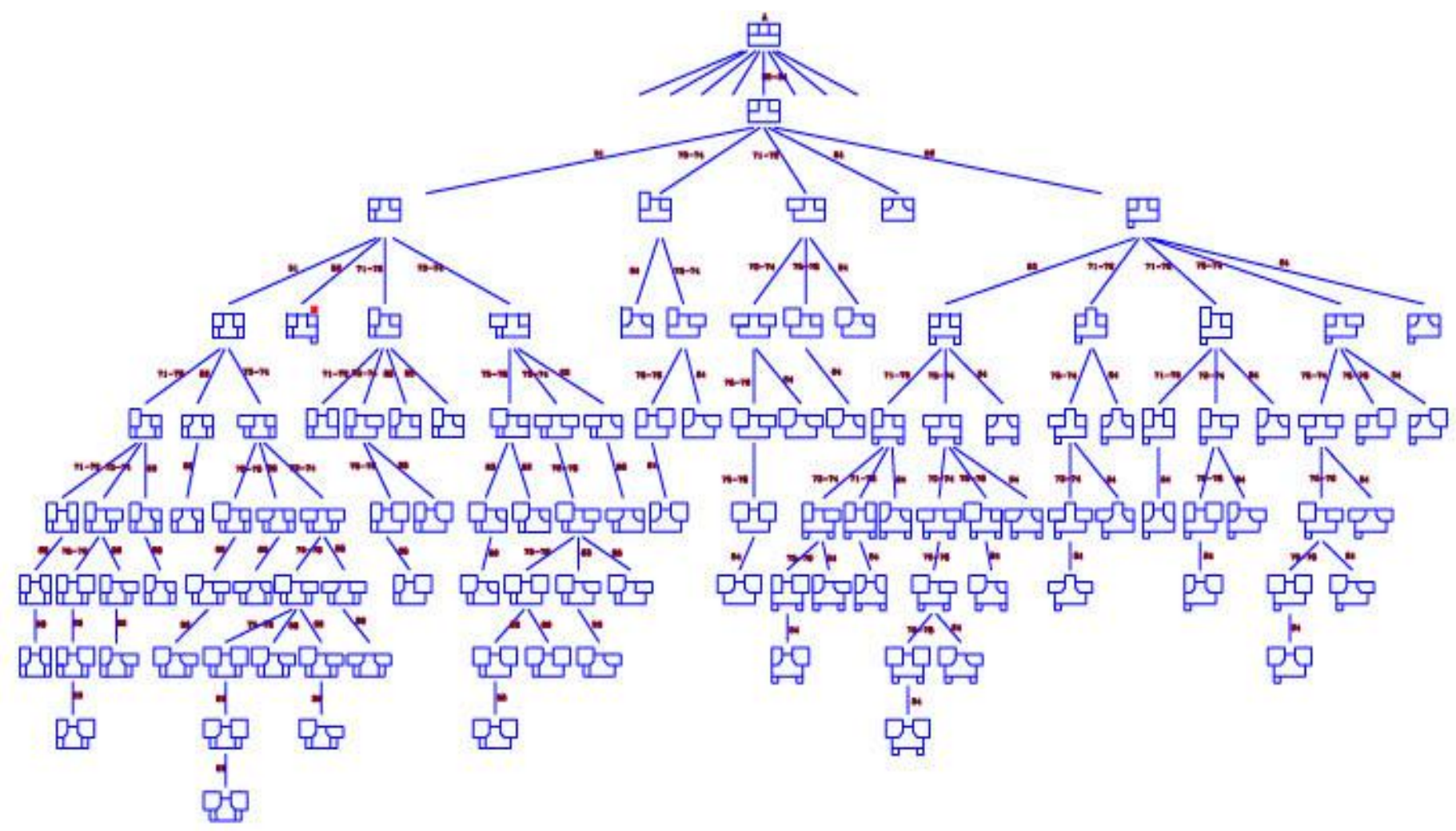

Figure 9. Part of the Tree of Plan Layouts with an Inner Hall Generated by the Shape Rules. Source: (Cagdas, 1996 adapted by the Author).

The start of the graph and design process is a point converted into space. The branch comes up with a new layout, which is not still associated with the house schema. Infinite designs can be achieved by continuing to apply different laws to different shapes (Hasani and Borazjani, 2018).

\section{CONCLUSION}

The shape grammar design alternative that presented in this paper explains the formal composition of the ground floor plans in Al-Lwibda residential houses by specifying shape rule schemata. The grammar accommodates the plan elements like the rooms, hall, Diwan, and Bays. As the language of AlLwibda, houses have the same vocabulary elements and different types of plans may have similar syntax and similar formal characteristics. These alternatives, which has a morphological module, the spatial relations in the plan layouts are represented by substitution rule-sets. As the room type determines the plan type of a house, the number of rooms is considered the initial shape of the grammar. The generative structure of this module is flexible to generate plan layouts alternatives of other houses which can be extended by combining one or more plan types, Figure 10.

This grammar expresses the design knowledge by using shape rule schemata. These schemata describe how to derive one compositional configuration from another. Thus, it explicates the design process of the language of Al-Lwibda residential houses. The syntactic and formal knowledge about the vocabulary elements and the spatial relations among them, which is given in the form of set grammar rules here, can be defined parametrically. Spaces with different dimensions and numbers can be generated by changing constraints on parameters. 

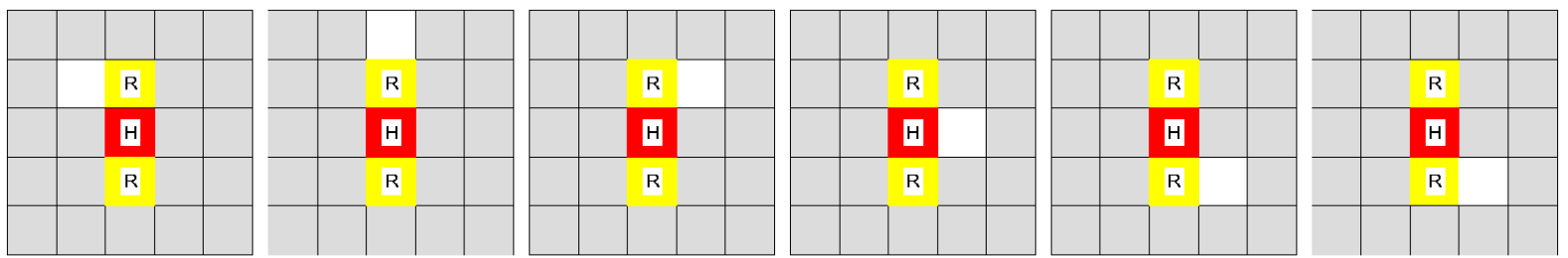

Generated Plan Layout with 2 Rooms
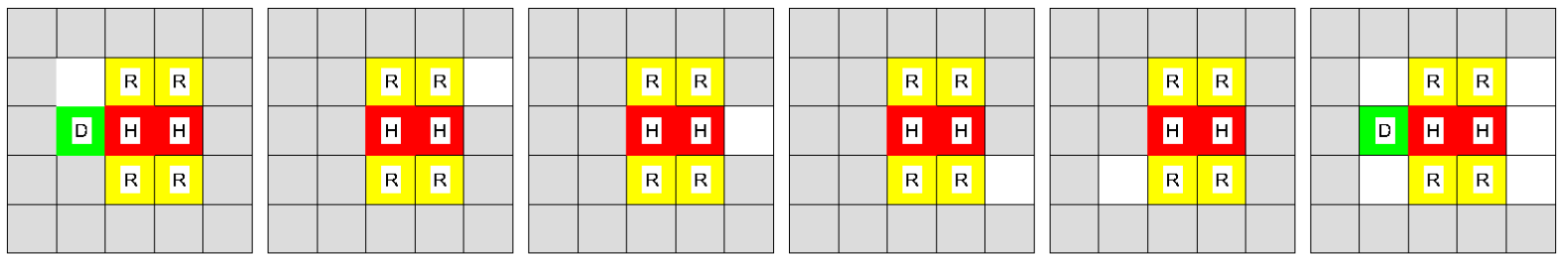

Generated Plan Layout with 4 Rooms and Diwan
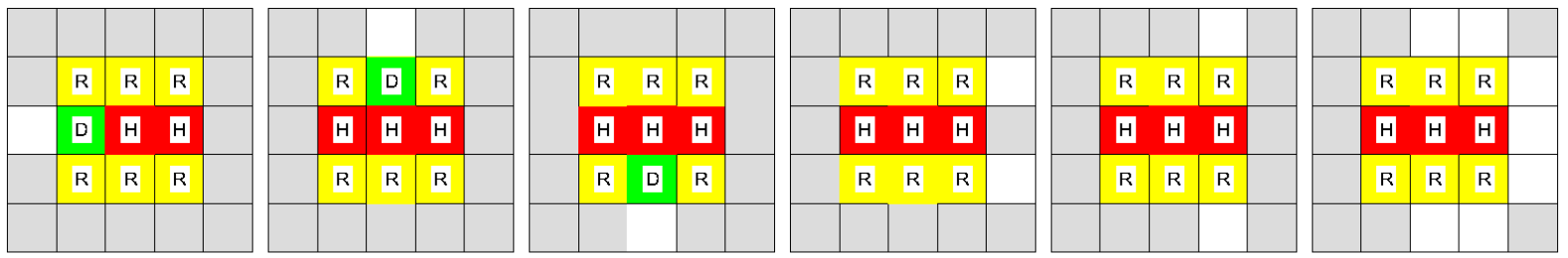

Generated Plan Layout with 6 Rooms and Diwan

Figure 10. Generated Plan Layout Alternatives. Source: (The Author, 2020).

The rule-sets of the parametric shape grammar have been applied to two-dimensional plan layouts. This grammar is a means of capturing the knowledge appropriate to the compositional configuration of the plan elements in the residential houses. The interpretation of this style and the formal knowledge acquired from the interpretation can be used to generate new designs. It also intends to provide a tool for exploring the compositional aspects of an architectural language by using a computer-based generative approach (Cagdas, 1996).

The educational value of the shape grammars is very useful. The generation process of designs can be made explicit by specifying the shape rules. The shape grammar that suggested in this study helps to facilitate the students' understanding of the formal compositions of Al-Lwibda residential houses. Like other shape grammars, it provides a computational simulation of the development and the modification of designs, and thus helps the students to understand the formal aspects of these houses style and to transfer the knowledge derived from this grammar to future house designs, as design precedents.

Thus, students learn the plan layout types, design components, and the rules to combine these components. These steps create the generation process, which are not separate processes. New plan layouts are generated based on a same shape grammar. Applying different rules for generation process end up with different plan layouts. Students are able to memorize these numerous plan layout alternatives and use them in other designs.

As future developments, the suggested module can be introduced into the formal studio environment and the evaluation of the quality of student work should be done through critics and competitions.

\section{ACKNOWLEDGMENT}

This work has been carried out during sabbatical leave granted to the author Wael Waleed Al-Azhari from the University of Jordan during the academic year 2017/2018.

\section{REFERENCES}

[1] Abu Ghoush, M. 2012. The Role of Adaptive Reuse and Rehabilitation for the Built Environment in Urban Regeneration: Selected Cases from Jabal Amman and Jabal Al-Weibdeh Neighborhoods. Unpublished Master Thesis, Department of Architecture Engineering, the University of Jordan.

[2] Al Adayleh, M. 2018. Architecture Heritage in Amman Options for Community Development: The Case of Jabal Al-Weibdeh. Unpublished Master Thesis, Department of Architecture Engineering, the University of Jordan.

[3] Cagdas, G. 1996. A Shape Grammar: The Language of Traditional Turkish Houses, Environment and Planning B, Planning and Design, (5), 443-464.

[4] Coyne, R.1988. Logic Models of Design. Pitman: London.

[5] Daher, R. 2009. Global Capital, Urban Regeneration and Heritage Conservation in the Levant. 22-26. In: Calabrese, J. (Ed.) The Middle East Institute Viewpoints: 
International Journal of Engineering Research and Technology. ISSN 0974-3154, Volume 13, Number 10 (2020), pp. $2526-2535$

(C) International Research Publication House. https://dx.doi.org/10.37624/IJERT/13.10.2020.2526-2535

Architecture and Urbanization in the Middle East.

[6] Daher, R. 2014. Urban Heritage and the Contention between Tradition, Avant-Garde, and Kitsch: Amman's Rising "Kitsch Syndromes" and its Creeping Vernacularized Urban Landscapes. Ethnologies, (6), 5575.

[7] Dilworth, G. 2017. Jabal Al-Weibdeh: a CounterMemory of Amman a Case Study in the Resistance of Memory. Independent Study Project (ISP) Collection: University of Virginia.

[8] Guzelci, O. 2014. A Shape Grammar Based Expert System to Generate Traditional Turkish House Plan Layouts. In: 17th Program of the Xvii Generative Art Conferencel Exhibition and Live-Performances, 294305. Rome: Politecnico di Milano University.

[9] Hasani, K., Borazjani, V. 2018. A Specification of a New Pattern of Shape Grammar in Architecture of Today's Houses, Case Study: Qajar Houses in Tabriz and Tehran. Bagh-e Nazar, 15 (63), 33-42.

[10] Knight, T. 1981. The Forthy-One-Steps. Environment and Planning B: Planning and Design, (8), 97-114.

[11] Knight, T. 2000. Shape Grammars in Education and Practice: History and Prospects. The Department of Architecture School of Architecture and Planning, Massachusetts Institute of Technology: Cambridge, MA.

[12] Knight, T., Stiny, G. 2001.Classical and Non-Classical Computation. Architectural Research Quarterly, (5), 355-372.

[13] Krishnamurti, R., and Giraud, C. 1986. Towards A Shape Editor - The Implementation of a Shape Generation System. Environment and Planning B: Planning and Design, (13), 391-404.

[14] Mitchell, W., Liggett, R., Pollalis, S., and Tan, M. 1991. Integrating Shape Grammars and Design Analysis. 1932. In: Schmitt, G. (Ed.) CAAD Futures'91. Vieweg \& Sohn, Wiesbaden.

[15] Raphael, B. 1976. Natural Language. In: The Thinking Computer: Mind Inside Matter, 177-210, Stanford Research Institute, A Series of Books in Psychology.

[16] Stiny, G. 1980. Introduction to Shape and Shape Grammar, Environment and Planning B: Planning and Design, (8), 343-351.

[17] Stiny, G., Gips, J. 1972. Shape Grammars and the Generative Specification of Painting and Sculpture. In Information Processing 71, 1460-1465. Amsterdam: North-Holland.

[18] Tapia, M. 1999. Visual Implementation of a Shape Grammar System. Environment and Planning $B$ : Planning and Design, (26), 59-74.

[19] The University of Jordan Publications. 2010. Analysis of the Architectural Styles of the Residential Buildings in the Area of Waibdeh 1953-2010: The Case Study Mohammed Al-Shoriki St. Jabal Al-Waibdeh/ AmmanJordan, (by Hoor, A., Shaheen, M., and Absi, M.), in: Yehia AlZoubi 'Design Theories' Master Course,
Department of Architecture Engineering, the University of Jordan (in Arabic).

[20] Trescak, T., Esteva, M., and Rodriguez, I. 2012. A Shape Grammar Interpreter for Rectilinear Forms. Computer Aided Design, (44), 657-670.

[21] Wojtowicz, J., Fawcett, W. 1986. Architecture: Formal Approach. Academy Editions: London. 